\title{
POESÍA COMPROMETIDA: ¿UN COMPROMISO PARA LA ACTUALIDAD?
}

\begin{abstract}
Gregori i Gomis Alfons, Poesía comprometida: ¿un compromiso para la actualidad? [Committed poetry: A real jam for present time?]. Studia Romanica Posnaniensia, Adam Mickiewicz University Press, Poznań, vol. XXXI: 2004, pp. 49-57. ISBN 83-232-1353-4, ISSN 0137-2475.

The essay Littérature et engagement: De Pascal à Sartre, written by the Belgian Benoît Denis, presents several critical problems about poetry and commitment. In the present article we will analyze some of these questions taking into account some important points about the changing of connotations and interpretations on forms of poetry and on poetry itself in the last century. Furthermore, this process of analyzing will provide a reconsideration of nowadays approximations to committed poetry from the critical point of view.
\end{abstract}

El terreno de la literatura comprometida no parece estar demasiado de moda entre los investigadores de la actualidad, aunque constituya un espacio de escriura amplio en los más diversos territorios. Se da por sentado, en muchas ocasiones, que se trata de un ejercicio textual más ideológico que literario. A nuestro parecer, también faltan aproximaciones críticas de carácter global que den cuenta de estas formulaciones literarias en su contexto, sin prejuicios ideológicos o estéticos que la mantengan en las mazmorras de la ignominia. Una posible excepción a esta realidad sería la obra Littérature et engagement: De Pascal à Sartre, del belga Benoît Denis, aunque por diversos motivos no se pueda considerar ni global ni libre de influjos tendenciosos. En el presente artículo vamos a focalizar nuestra atención en ciertos problemas que surgen a la hora de leer entre líneas algunos de sus fragmentos, en los cuales se hallan determinados elementos fundamentales de la cosmovisión de su autor, ampliable a una parte destacada del mundo de la crítica literaria. Al mismo tiempo, repasaremos sumariamente aspectos históricos y interpretativos de la poesía en su vinculación con el compromiso literario, sobre todo a partir del análisis de la problemática mencionada previamente. Al parecer de Denis (2000: 19-23), una tríada de factores marcan el nacimiento de la concepción moderna de la literatura 
engagée: La aparición de un campo literario autónomo alrededor de 1850 , que crea la visión moderna de lo literario; el nacimiento, a caballo de los siglos XIX y XX, del rol social del intelectual, situado al margen de la literatura y la Universidad; y el estallido y triunfo (si es que puede hablarse de triunfo) de la Revolución ${ }^{1}$ de octubre en la Rusia de 1917, que mantuvo un enorme poder de atracción de intelectuales y escritores posteriores como acontecimiento político con aura fundacional.

Precisamente, el primero de los factores mencionados anteriormente, la autonomización del campo literario propio de la modernidad, invita a plantearse el modelo o proceso de categorización llevado a cabo por la crítica al respecto de lo literario y el engagement. Tal modelo o proceso puede convertirse en un configurador de postulados normativos o paranormativos, de paradigmas más o menos dominantes, $o$ de tendencias generales, en una escala con muchos eslabones intermedios. Observemos cómo explica Denis (2000: 20) la posición del escritor en la modernidad literaria: «S'instaure, donc, vers 1850 une vision de la littérature, qui a pris le nom de modernité, en vertu de laquelle l'écrivain refuse de se sentir redevable ou solidaire de la société générale et, partant, de prendre part aux débats et aux luttes qui l'agitent [...]». El término "visión" resulta muy amplio y difuso. El texto completo de Denis da la impresión de querer transmitir a veces una idea de "tendencia general", pero en no pocas ocasiones se alza como un postulado normativo, en el sentido que no resulta una opción sinó una situación dada, esencializada como lo "normal". A nuestro parecer, esta visión se acaba configurando en el texto de Denis como un paradigma, en cuyo seno la voz de este crítico participa de otras presencias discursivas, como las teorías sartrianas o los planteamientos del movimiento simbolista. Al mismo tiempo, esta "visión" se ha acabado convirtiendo en un elemento importante en la jerarquización del arte. En tal jerarquización, el grado mayor se alcanza mediante la pureza de lo "supra"-político, lo "supra"-social y lo "supra"-económico. Así, el paradigma de la modernidad artística ha invadido los diferentes campos artísticos y se ha entrelazado con otros elementos para tejer una red de significaciones fuera de la cual la palabra "arte" carece de aquellos rasgos que la hacen intelectivamente recognoscible como tal. En este sentido, la denominación inventada por Barthes de «écrivain-écrivant» manifiesta al escritor comprometido como un personaje "bastardo", como el producto de una mezcla impura (Denis, 2000: 21).

De esta visión de la modernidad surgen una serie de preguntas que hoy son un clásico retórico, como por ejemplo hasta qué punto las formas artísticas pueden servir a un proyecto de organización social sin traicionar su naturaleza "artística", e incluso la libertad (Tackels, 2000: 88). Evidentemente, estas preguntas fueron pertinentes en determinados momentos, $y$ han sido cuestiones clave en pensadores como Walter Benjamin. Con todo, debemos situarlo en su contexto histórico, es decir, en pleno auge del fascismo en muchos países de Europa. Quizás el error

' A veces, la auto-referencialidad nacional de Denis (2000: 22) llega a desconcertar, con afirmaciones como la siguiente: «ll y a d'abord un attachement typiquement français à l'idée de révolution». 
consiste en plantear el tema de las relaciones entre ideología y arte como una relación de servitud, cuando precisamente la orientación podría ser la contraria. O sea, ¿hasta qué punto, en la modernidad de la cual todavía no nos hemos salido, la ideología progresista en ciertas sociedades no se encuentra al servicio del arte y de la libertad artística? ¿No puede el poder de estado convertirse en un instrumento descentralizado, deslocalizado y objetivo (en un sentido no ingenuo), dentro de unas coordenadas verdaderamente democráticas? Probablemente, nuestra perspectiva a través de los años nos ha mostrado un camino espinoso, pero igualmente menos pesimista y dramatizado que a Benjamin, por lo cual su preocupación se mantiene palpitante pero se puede enfocar desde otros puntos de vista, en los cuales los conceptos de proletariado y de burguesía han pasado a la Historia, y nos hallamos frente a una realidad de los aparatos de poder mucho más voluble, difuminada y, hasta cierto punto, incognoscible.

El tercer punto que define Denis como punto de inflexión en relación al surgimiento de la visión moderna del compromiso se sitúa en la Revolución rusa. Claro está que en gran medida se ha entendido la literatura comprometida como el brazo ejecutor en lo cultural de los objetivos revolucionarios. Sin embargo, desde una perspectiva más global y serena, no podemos quedarnos con tal ligazón, sino que el texto literario toma vida propia más allá de revoluciones particulares y cuestiones ideológicas locales para tender hacia lo universal. En este sentido, lo particular de cada territorio presenta unos rasgos ideologizados por factores históricos y relaciones de poder. El crítico polaco Edward Możejko (2001: 307) y su importante obra Realizm socjalistyczny: Teoria, rozwój, upadek suponen una buena muestra de ello. Así, Mozejko señala las deficiencias del tratamiento del realismo socialista como "método de creación" en la obra de Regine Robin Le réalisme socialiste: une esthétique impossible (1986), en la cual este "método" es visto como un logro derivado de una supuesta búsqueda por parte de los artistas de la Unión Soviética en los años veinte del siglo XX, cosa que evoca de manera sorprendente las directrices de la crítica oficial del régimen totalitario según las cuales los propios escritores elaboraron el programa del realismo socialista. Tales concomitancias exaltan la sensibilidad crítica de Możejko, exiliado muchos años en Estados Unidos como su compatriota Czesław Miłosz.

El realismo socialista, oficializado en el Congreso de Escritores Soviéticos de 1934, se convirtió en una etiqueta que ha acabado vinculando unívocamente compromiso con un escritura realista ${ }^{2}$. A todo ello contribuyeron eslóganes simples y efectivos, como aquél de Gorki que aclamaba al realismo socialista como heredero

${ }^{2}$ Durante el Congreso de Escritores Soviéticos de 1934 y en sus contornos temporales, las corrientes literarias del formalismo y del modernismo fueron condenadas por diversas voces en los debates que allí se desarrollaron (Robin, 1986: 42), aunque la máxima del "método creativo" permitió unos diez años de "paz" formal hasta que una serie de anónimos en el Ipaeda abrieron una campaña contra el formalismo y el naturalismo, las dos "herejías" más detestadas por la ortođoxia soviética (Aucouturier, 1998: 64). 
de las mejores tradiciones literarias del mundo; aunque en este caso sólo se tratara de un intento de "legalizar" la noción de realismo socialista como concepción literaria productiva (Możejko, 2001: 45). Sin embargo, la formulación estética de la utopía, de aquello a lo que se aspira, en principio, tendría que encontrar su correspondencia más directa en elementos estéticos vinculados a lo irreal. El realismo supone un eje posible de consciencia crítica, pero los horizontes se abren a to desconocido y lo sugerente en una literaria comprometida con unos objetivos determinados más allá del presente. En un debate particular con György Lukács sobre literatura y revolución, Ernst Bloch defendía el compromiso políticamente progresista del Expresionismo por la capacidad de este modelo literario y artístico de mostrar gráficamente la confusión, la inmadurez y la incomprensión, es decir, los rasgos emotivos de aquel capitalismo enfermizo que pas por sus años de crisis, entre la Primera Guerra mundial y las dictaduras fascistas (Travers, 2001: 201). Entonces, el territorio de la Unión Soviética como "madre de todas las batallas" en lo que a compromiso literario respecta, y una vez eliminado el vanguardismo revolucionario de tendencias proletaristas, se encuentra con la competencia de un eje de producción de alto voltaje, que Denis no toma en cuenta: La Alemania de Erbschaft dieser Zeit (1934) (Herencia de nuestra época) de Ernst Bloch o Das Kunstwerk im Zeitalter seiner technischen Reproduzierbarkeit (1936) (La obra de arte en la época de su reproductibilidad técnica) de Walter Benjamin.

En todo caso, si se opta por considerar que el compromiso literario no puede coincidir ni ideológica ni fácticamente con el monologismo político ( $\mathrm{y}$ aquí utilizamos la terminología bajtiniana de forma expresa), cualquier impulso de instalar la estética del realismo socialista salida de la Unión Soviética en el marco interpretativo de la poesía engagée constituye una desviación fuera de lugar. Si se quiere, más que una "desviación" (término que evoca lo herético), se trató de un infeliz y encegado incidente de la historia literaria que se produjo en su mayor parte durante los años de la posguerra en los países de Occidente. Sus intelectuales progresistas todavía no habían podido o no se habían atrevido ${ }^{3}$ a apartar el velo de Maya mitificador que oculataba tras el Telón de Acero un violento y opresivo sistema político, social, económico y cultural. Raymond Williams (1977: 229) denuncia desde la crítica marxista contemporánea el engaño que supone pensar que las directrices soviéticas en lo literario tenían que ver con el compromiso y el arte socialistas: "[...] en nombre del socialismo, numerosos escritores fueron engatusados, reprimidos e incluso destruidos". En verdad, la vaguedad de la definición de realismo socialista del Congreso de 1934 se corresponde de maravilla con las siguientes palabras de Mao Tse-tung, etéreas e hipócritas, pero que tanto éxito tuvieron posteriormente entre los decepcionados del sistema soviético: "Es nocivo para el crecimiento del arte y la ciencia si las medidas administrativas son utilizadas

${ }^{3}$ Esta última variante debe tenerse en cuenta sobre todo a partir del XX Congreso del Partido Comunista en la Unión Soviética de 1956, en el cual el informe presentado por Kruchov sacó a la luz y atacó duramente algunos de los actos criminales del estalinismo. 
para imponer una escuela de pensamiento y un estilo particular de arte y prohibir otro" (Williams, 1977: 232). El pasado parece conectarse con el futuro a través del rasgante hilo de la ironía que borda sobre la historia cuando observamos a intelectuales españoles (peninsulares) obviando el hecho macabro que Fidel Castro continúe encarcelando escritores de la oposición.

Decíamos que la obra de Denis no estaba libre de influencias que la conducían hacia lo tendencioso. En concreto nos referimos a Sartre y a su visión del engagement en el libro Qu'est-ce que la littérature, el cual es considerado por Denis (2000: 13) no sólo como «[...] le texte qui a envisagé le plus complètement la question de l'engagement en littérature» o el que ha dado su formulación más extensa y completa, sino como el texto más importante jamás escrito sobre el compromiso literario y el "horizonte de referencia" de cualquier tentativa de descripción del fenómeno (Denis, 2000: 28-29). No obstante, sabemos que se trata de una obra que ha sido matizada y contradecida (cuando no desprestigiada) en sus argumentos por la mayoría de críticos dedicados a la cuestión, des de su mera aparación hasta nuestros días ${ }^{4}$. Su consideración de la poesía como un género per se incomprometible la convierte en una textualidad claramente amoral: «Or, comme c'est dans et par le langage conçu comme une certaine espèce d'instrument que s'opère la recherche de la vérité, il ne faut pas s'imaginer qu'ils [los poetas] visent à discerner le vrai ni à l'exposen’ (Sartre, 1948: 18). A ojos de la escritora Iris Murdoch esto se traslada al abandono por parte del escritor francés de lo que ella etiqueta como "the complexity of the world of ordinary moral virtues" (Mander, 1961: 12). Adorno (1962: 189) ya aclaró las cosas de forma harto sintética cuando escribió que el escritor, a diferencia de lo subrayado por Sartre, no sólo se acara con significados: "If no word which enters a literary work ever wholly frees itself from its meaning in ordinary speech, so no literary work, not even the traditional novel, leaves these meanings unaltered, as they were outside it". Fijémonos, además, en las siguientes palabras del filósofo francés (1948: 18): „Ils [los poetas] ne songent pas non plus à nommer le monde et, par le fait, ils ne nomment rien du tout, car la nomination implique un perpétuel sacrifice du nom à l'objet". Así, y tomando como referencia el papel del lenguaje en el Génesis bíblico, el único que puede alzarse como verdadero creador de mundos es el prosista ${ }^{5}$. Sartre, pues, niega al poeta el

${ }^{4}$ Una muestra de un punto de vista diferente al de Denis es el estudio de Martin Travers (2001: 208), en el cual la obra y cl pensamiento de Sartre accrca del compromiso son situados después de Camus, en un reducido espacio al final de un recorrido argumentativo a lo largo del siglo XX. Incluso el mismo Denis (2000: 64-65) admite que la obra ha sido descalificada con frecuencia, principalmente en lo que respecta al desinterés por la dimensión estética de las obras y a la distinción entre artista (inclusive los poetas) y escritor (de prosa).

${ }^{5}$ En este sentido, la moralidad constituye, paradójicamente, un elemento central en el discurso al entorno de la literatura de este filosofo francés ateo, ya que Dios, al das un nombre a las cosas, crea y, al mismo tiempo, se otorga personalidad moral, como responsable de unos elementos que le pertenecen y que se constituyen como algo bueno, positivo, por su naturaleza de origen divino, en un marco general judeo-cristiano. 
poder de manipulación del mundo, de apropiación del mundo, algo increible en el contexto de un siglo XX dominado, dentro del campo de la reflexión filosófica, por las investigaciones sobre el lenguaje y su capacidad de condicionar o determinar la "realidad objetiva".

Denis (2000: 69) intenta justificar los postulados de Sartre asegurando que en ellos la preocupación formal no resulta incompatible con la elección del compromiso: El único requisito es que la forma no puede ser independiente, no puede poseer un significado paralelo, otro, que pueda llegar a contradecir el "fondo" de la obra, sino que de un modo u otro debe quedar al "servicio" de éste. La "cierta" manera que el engagement sartriano supone, según Denis (2000: 42), de creer en la literatura y en sus "poderes", a pesar de los supuestos postulados humanistas que la han justificado, se derrumba minada de contradicciones y de falsos presupuestos. $\mathrm{Si}$ bien Denis se une a Sartre en la crítica a la visión literaria radicalmente intransitiva de la modernidad, no se entiende demasiado el motivo de la obstinación en incluir también toda la poesía dentro de ese gran saco oscuro de la poética intransitiva, con una despreocupación absoluta (e irresponsable) por los efectos que la poesía social estaba cosechando en territorios tan cercanos como Cataluña, bajo la dictadura de Franco. Denis (2000: 71) llega a definir la poesía como un "punto ciego de la práctica literaria", ya que constituye el género literario más valorado en la modernidad por sus supuestas características inherentes de "objeto autónomo" auto-teleológico y auto-reflexivo. Cabría preguntarse seriamente si aquí el crítico no está identificando falsamente la visión del planteamiento simbolista sobre el poema con un conjunto de características esenciales de la poesía que el compromiso sartriano no podría aceptar de ningún modo ${ }^{7}$.

Moviéndonos todavía en el terreno de la poesía y su capacidad de compromiso, cabe hacer mención de las referencias de Galuano Della Volpe (1963: 113) a los orígenes platónicos de la separación entre poesía y comunicabilidad, ya que ponen sobre la mesa un pensamiento que se ha incrustado en los textos literarios y paraliterarios de toda la historia occidental. Así, Della Volpe (1963: 113) habla de "los textos platónicos acerca de la naturaleza irracional de la poesía en cuanto manía, posesión o «furor» divino, cort el consiguiente desprecio del «saber»o técnica (reglas) en esa poesía", Kant de la obra Kritik der Urteilskraft (1790) (Crítica de la facultad de juzgar o Crítica del juicio), que designa a la poesía como una "finalidad sin finalidad" (Della Volpe, 1963: 136), es decir, una entidad textual auto-teleológica el sentido de la cual se diluye en la nada del sin-sentido. Y más adelante tendrá un peso en el

'Observemos, de pasada, el uso de una terminología tal como "estar al servicio de", que evoca el lenguaje y el empobrecido trasfondo marxistas que se filtraban en mentes como la de Sartre.

7 Denis (2000: 72), afirmando en defensa de Sartre que éste "no condenaba" la poesía, llega a reificar este tipo de escritura artística como género del siguiente modo: «Elle [la poesía) est ce qu'elle est et il n'y a pas lieu de lui demander d'être autre chose, sans quoi elle ne serait plus poésie».

${ }^{8}$ La cursiva en este caso es del original. 
proceso la linguística humboldtiana y romántica de la palabra, a causa de lo que Della Volpe $(1963: 134,136)$ subscribe como "indiferentismo lingüístico", y los "epígonos" del cual serán los simbolistas. De este modo, el poeta romántico británico Coleridge empezó a mostrar en sus escritos críticos una visión de la poesía opuesta a la ciencia y, consigüientemente, irracional (Castellet, 1965: 185). Todo ello se une en lo que el poeta simbolista Paul Valéry analiza en sus Cahiers: La necesidad insaciable de originalidad en literatura desde una perspectiva sociopolítica modema, en tanto que a su parecer en el siglo XIX la noción de revolución o rebelión se volvió la expresión de una transformación (violenta o no) de lo que existe, sea lo que sea, por lo que el cambio en sí se convirtió en lo más importante (Bessière \& Michaud, 2001: 7). La originalidad asume un valor en sí inherente al experimentalismo vanguardista, desvinculándose rápida y radicalmente de los valores morales y políticos de la sociedad: La originalidad se convierte en un elemento abstracto e independiente, un motor autónomo de creación que repugna cualquier signo de estabilidad, también en lo social, alzando un alto muro entre cualquier idea estable de Bien y el valor inexorable del cambio.

No se puede negar, en cualquier caso, que Della Volpe y otros críticos de la época cayeron en preceptos marxistas simplificados. Su perspectiva acerca del realismo socialista en oposición al experimentalismo vanguardista en Occidente resulta una evidencia de ello, sobre todo en su lacónico y contundente artículo "Sobre el concepto de "vanguardia»", en el que podemos leer lo siguiente: "[...] A los materialistas marxistas el término y el concepto de vanguardia no pueden sernos útiles. [...] En nuestra lucha por una nueva poética debemos substituir este término por el de realismo socialista" (Della Volpe, 1963: 229). El "occiden-talismo" de la propuesta dellavolpiana se observa en la reivindicación de las figuras literarias de Brecht y Mayakovski como ejemplos de la poética del realismo socialista y de revuelta contra las vanguardias literarias (Della Volpe, 1963: 229). Achaca el estudioso italiano al vanguardismo la chacra de ser un término excesivamente cargado históricamente, que ha acabado por convertirse en un sinónimo de formalismo, y del cual solamente se salva su actitud antiacadémica y su aversión tanto a la formas y técnicas artísticas tradicionales como a sus contenidos retóricos (Della Volpe, 1963: 228). Evidentemente, una posición de estas características, tan en voga en los círculos progresistas europeos occidentales, comporta ciertos obstáculos en vistas a dilucidar, situar y valorar sin prejuicios los componentes verdaderamente comprometidos de una obra de arte en poesía.

La colectividad que existe en el Occidente actual no puede remitirse a aquellas simplificaciones que operaban entre bloques sociales estancos. Por el contrario, esta nueva colectividad lectora se ha quitado la máscara de clase social única que algunos le habían impuesto (léase "proletariado" o "burguesía") y desea danzar en el espacio literario dialogando con lenguas, tonos y metas distintos. Consideramos, pues, válidas todavía las reflexiones sobre la sociedad y lo social de Adorno, que nos pueden ser de gran ayuda a la hora de visualizar la función del artista como 
sujeto individual, las obras como representación artística en el seno de la sociedad, y los lectores, que en su potencialidad son la personificación (siempre parcial) de la sociedad": "While the notion of society may not be deduced from any individual facts, nor on the other hand be apprehended as an individual fact itself, there is nonetheless no social fact which is not determined by society as a whole" (Jameson, 1971: 57). El autor italiano Salvatore Quasimodo (1974: 275) dejó escrito un fragmento sobre la poesía en su dimensión humana (y social) que por su sencillez demuestra su maestría intelectual: "[...] La poesia nasce con l'uomo, e l'uomo nella sua verità non è altro che bene più male". Es decir, que la poesía se puede relacionar con la moral en un plano general, pero sin establecer identificaciones o elaborar connotaciones que categorizen sus figuraciones particulares en campos cerrados a lo moral y a lo político. Recordemos, aunque sea de más, que vivimos en sociedad, que somos seres políticos, y que la polis no debe olvidar la poiesis, pues ambas nacen de lo plural y no de lo monolítico o monológico.

El mismo engagement debería ser considerado, abiertamente, como una modulación de lo poético que, gracias al proceso de alegorización conduciente del pathos al ethos, puede superar los límites temporales e ideológicos de su época para resultar igualmente comprometida en otros espacios y tiempos. Por lo que tampoco debe ser reducido a una estética determinada, sea el realismo más clásico, el vanguardismo más experimental o cualquier otra que pueda aparecer en el futuro. La poesía comprometida no puede ser normativizada ni ancorada en paradigmas que la limiten. Hay que liberarla en una multiplicidad de sentidos dentro de un marco de comunicabilidad de elementos ideológicos o ideologizados que responda a la pluralidad de valores de la actualidad y del futuro. En todo ello, la forma se posiciona como mediadora, una entidad poliédrica que asume analógicamente el peso de lo social y que, en definitiva, permite la calificación de arte para el poema resultante. Es decir, la unión entre ética y estética supone una distanciación que posibilita al lector la realización de un desplazamiento interno más allá de lo que se entiende por "emoción estética". Los modelos de interpretación y análisis de la poesía en un marco engagé han de ser capaces de sacar a la luz aspectos de la poesía comprometida que pongan en relación ideología, realidad histórica y también, muy especialmente, la forma. Albert Camus lo comentaba de manera extremadamente sugerente en uno de sus escritos: «La beauté, sans doute, ne fait pas les révolutions. Mais un jour vient où les révolutions ont besoin d'elle» (Bessière \& Michaud, 2001: 7).

\footnotetext{
'La perspectiva proporcionada por el término "sociedad" frente a la expresión más coloquial "pueblo" resulta considerablemente importante para pasar de un estado mesiánico del rol poético a una visión global pero distanciada y comprehensiva del conjunto de personas que habitan un territorio. Sin embargo, el mecanismo dialéctico funciona continuamente: Como explica Aucouturier (1998: 77), la noción de "pueblo", extraña al marxismo soviético, fue introducida por Lifchits y Lukács para explicar la universalidad de un arte que trasciende las limitaciones de clase.
} 


\section{BIBLIOGRAFÍA}

Adorno, T.W. (1962). Commitment, en Terry Eagleton \& Drew Milne (eds.). Marxist literary theory: A reader. Oxford: Blackwell, 1996, 187-203.

Aucouturier, M. (1998). Le réalisme socialiste. Que sais-je? 3320. París: PUF.

Bessière, J. \& Michaud S. (2001). Introduction, en J. Bessière \& Michaud S. (eds.). La main hâtive des révolutions: Esthétique et désenchantement en Europe de Leopardi à Heiner Mäller. Page Ouverte. París: Presses de la Sorbonne Nouvelle, 7-14.

Castellet, J. M. (1957/1965). L'hora del lector / Poesia, realisme, historia. Pról. de J. F. Yvars. L'alzina, 18. Barcelona: Edicions 62, 1987.

Della Volpe, G. (1963). Crítica del gusto. Trad. de Manuel Sacristán. Biblioteca Breve. Barcelona: Seix Bartal, 1966.

Denis, B. (2000). Littérature et engagement: De Pascal à Sartre. Points / Essais, 407. París: Seuil.

Jameson, F. (1971). Marxism and Form: Twentieth-Century Dialectical Theories of Literature. Princenton: Princenton University Press.

Mander, J. (1961). The Writer and Commitment. Londres: Secker \& Warbung.

Mozejko, E. (2001). Realizm socjalistyczny: Teoria, rozwój, upadek. Cracovia: Universitas.

Quasimodo, S. (1974). Poesie e discorsi sulla poesia. Ed. de Gilberto Finzi. Pref. de Carlo Bo. $3^{\mathrm{a}} \mathrm{ed}$. Milán: I Meridiani.

Robin, R. (1986). Le réalisme socialiste: Une esthétique impossible. Aux Origines de Notre Temps. París: Payot.

Sartre, J.-P. (1948). Qu'est-ce que la littérature? Folio / Essais, 19. París: Gallimard, 1985.

Tackels, B. (2000). Brecht ou le marxisme exilé. Europe: Bertold Brecht, 856-857, agosto-septicmbre, $80-93$.

Travers, M. (ed.) (2001). European literature: From Romanticism to Postmodernism (A reader in aesthetic practice). Londres-Nueva York: Continuum.

Williams, R. (1977). Marxismo y literatura. Trad. de Pablo di Masso. $2^{\mathbf{a}}$ ed. Historia, Ciencia, Sociedad, 265. Barcelona: Península, 2000. 